\title{
Conhecimento e utilização do Biobanco de Dentes Humanos pela comunidade acadêmica do curso de Odontologia da UFPR
}

\author{
Patrícia Larissa Gebauer*; Lucas Antico Dunaiski*; Idalina Marly Da Luz**; Yasmine Mendes \\ Pupo $^{* * *}$; Ivana Froede Neiva****; Andresa Carla Obici*****
}
* Graduando (a), Curso de Odontologia, Universidade Federal do Paraná
** Mestre em Distúrbios da Comunicação, Enfermeira do Biobanco de Dentes Humanos da Universidade Federal do Paraná
*** Doutora em Odontologia, Professora Adjunta, Departamento de Odontologia Restauradora, Universidade Federal do Paraná
**** Doutora em Biotecnologia, Professora Associada, Departamento de Odontologia Restauradora, Universidade Federal do Paraná
***** Doutora de Materiais Dentários, Faculdade de Odontologia de Piracicaba, Universidade Estadual de Campinas

Recebido: 14/12/2020. Aprovado: 12/09/2021.

\begin{abstract}
RESUMO
O objetivo deste estudo foi analisar o perfil dos usuários do Biobanco de Dentes Humanos da Universidade Federal do Paraná (BDH-UFPR), os serviços mais procurados, se há utilização de dentes obtidos externamente e o grau de satisfação dos usuários. Para isso, foi aplicado um questionário eletrônico semiestruturado à comunidade interna do curso de Odontologia da UFPR, entre agosto e dezembro de 2019. Um total de 300 questionários foram respondidos, sendo 263 por estudantes de graduação, 4 por pós-graduandos, 24 por professores e 9 por servidores técnico-administrativos. A maioria dos estudantes era do sexo feminino entre $17 \mathrm{e}$ 22 anos, enquanto para os servidores (professores e técnicos) houve uma distribuição semelhante entre os sexos na faixa etária entre 40 e 59 anos. Embora 80,99\% dos discentes afirmaram conhecer o BDH-UFPR, apenas 50,19\% usaram seus serviços e 59,32\% relataram já terem buscado dentes externamente. $\mathrm{O}$ serviço mais utilizado foi o empréstimo de dentes para atividades de ensino, porém apenas $42,15 \%$ os devolveram após o uso. Os dentes obtidos externamente foram provenientes, principalmente, de consultórios particulares e apenas $56,33 \%$ dos alunos relataram sempre ter submetido-os à desinfecção/esterilização, sendo a autoclave o método mais indicado. Todos os servidores conheciam o BDH-UFPR e, dentre os professores, a maioria realizou tanto empréstimos quanto doações. Os empréstimos tiveram como principal finalidade a pesquisa e 63,6\% relataram terem devolvido os dentes. Quanto à satisfação, a comunidade acadêmica mostrou-se predominantemente totalmente satisfeita. Por fim, ressalta-se a necessidade de ampliar as ações de conscientização para a comunidade acadêmica quanto aos aspectos éticos, legais e de biossegurança na aquisição e manipulação de dentes humanos.
\end{abstract}

Descritores: Dente. Ética Odontológica. Educação em Odontologia. Pesquisa em Odontologia. 


\section{INTRODUÇÃO}

A utilização de dentes humanos para a realização de pesquisas científicas e para o ensino na Odontologia é uma prática bastante conhecida. Entretanto, é de grande importância a existência de Biobanco e/ou Banco de Dentes Humanos, os quais podem ceder dentes para estas atividades de maneira segura e respeitando as leis e normas brasileiras vigentes ${ }^{1}$.

Um biobanco é responsável por armazenar coleção de material biológico humano e informações associadas, para fins de pesquisa conforme regulamento ou normas técnicas, éticas e operacionais pré-definidas, sob responsabilidade e gerenciamento institucional e sem fins lucrativos. Além de instalações de armazenamento, ele pode incluir uma organização completa, com amostras biológicas, dados, políticas e procedimentos para manusear essas amostras e realizar outros serviços, tais como a gestão do banco de dados e planejamento de estudos científicos ${ }^{2}$. Já os Bancos de Dentes Humanos são entidades sem fins lucrativos e vinculados a uma faculdade, universidade ou outra instituição que se responsabilizam pela coleta/recepção, limpeza, desinfecção, preparação, catalogação, armazenamento, cessão/empréstimo e administração dos dentes, bem como pela conscientização da população leiga, da comunidade acadêmica e da educação para a prática ética ${ }^{1,3}$. Em suma, o principal objetivo de um biobanco é fornecer material biológico para pesquisa, enquanto um banco de dentes está mais centrado na conscientização e na gestão de dentes para atividades de ensino. É dentro deste contexto que a criação e estruturação de Biobancos e/ou Bancos de Dentes Humanos nas instituições de ensino superior do país é de grande importância, visando principalmente minimizar o comércio ilegal de dentes humanos, que ainda acontece nos cursos de Odontologia, bem como disponibilizá-los de maneira segura e controlada para diferentes atividades de ensino, pesquisa e extensão ${ }^{3-5}$. Além disso, a polpa dentária obtida de dentes extraídos ou esfoliados é fonte de células-tronco, as quais podem ser aplicadas na medicina regenerativa e terapia de regeneração tecidual, constituindo um importante campo de pesquisa ${ }^{6}$.

A Faculdade de Odontologia da USP foi responsável pela criação do primeiro Banco de Dentes Humanos (BDH) do Brasil, o qual serviu para o reconhecimento do dente humano como um órgão, por meio da Lei n ${ }^{\circ} 9434$ de 4 de fevereiro de 19977. Outros BDHs começaram a ser instituídos no Brasil a partir dos anos 2000, tendo como objetivo desenvolver a percepção dos princípios de biossegurança e bioética entre os estudantes e profissionais da Odontologia, além de deter a responsabilidade pelas atividades que envolvem a manipulação e administração dos dentes $\operatorname{doados}^{3,5,8,9}$.

Os BDHs assumem uma importante função ética, pois minimizam ou mesmo eliminam o comércio ilegal de dentes humanos ${ }^{10}$, visto que a utilização de órgãos ou tecidos humanos sem procedência comprovada é considerada crime ${ }^{4,7}$. Ao longo dos anos, o número de BDHs nas instituições de ensino tem aumentado e atualmente estão distribuídos em todas as regiões brasileiras ${ }^{1,4,11}$. Contudo, segundo Freitas et al. (2012) ${ }^{4}$, embora o uso de dentes para pesquisa e ensino seja frequente na Odontologia, a existência dos BDHs é recente e incompletamente difundida nas instituições de ensino superior.

$\mathrm{O}$ BDH do Curso de Odontologia da UFPR foi inaugurado no dia 22 de junho de 2010 e em agosto de 2019, foi aprovado como biobanco pela Comissão Nacional de Ética em Pesquisa (CONEP), sendo responsável por gerenciar a captação, recebimento, processamento, catalogação, armazenamento e empréstimo de dentes humanos. Desta forma, é possível seu empréstimo de acordo com as 
normas éticas e de biossegurança, no intuito de atender às demandas dos cursos de graduação e pós-graduação ${ }^{2}$. Neste contexto, cabe ressaltar que o BDH da UFPR é vinculado ao Biobanco do Hospital de Clínicas da UFPR, o qual é responsável por normatizar o funcionamento dos biobancos e biorrepositórios da instituição, sendo gerido pelo Departamento de Odontologia Restauradora juntamente com o Programa de Extensão "Banco de Dentes da UFPR: educação em saúde".

Os dentes recebidos passam por procedimentos operacionais padrão (POP) de limpeza, desinfecção e/ou esterilização para, então, serem catalogados e armazenados nas diferentes coleções: dentes rastreáveis e dentes não rastreáveis. Os dentes rastreáveis são obtidos a partir da doação voluntária de pacientes atendidos nas dependências do curso, os quais são extraídos por indicação clínica de diferentes disciplinas. Para a doação, os pacientes assinam previamente o Termo de Consentimento Livre e Esclarecido (TCLE). Logo após a exodontia, os dentes são acondicionados em recipientes com tampa rosqueável contendo solução de ácido peracético a $1 \%$ e, então, encaminhados ao BDH onde são registrados, limpos, desinfectados e ficam armazenados em recipientes codificados com cloramina $\mathrm{T}$ a $0,5 \%$ sob refrigeração. Os dentes também são recebidos de unidades básicas de saúde (UBS) de Curitiba e região metropolitana, as quais assinam o Termo de Doação (TD) para que se faça a transferência dos dentes para o BDH. Estes dentes são armazenados na coleção de dentes não rastreáveis.

Todos estes procedimentos visam atender as demandas internas do curso de Odontologia da UFPR, incluindo as atividades práticas de ensino e extensão, assim como, fornecer dentes para a realização de projetos de pesquisa e iniciação científica. A estrutura do $\mathrm{BDH}$ da UFPR se consolidou de modo a organizar de maneira sistemática o acervo de dentes humanos, possibilitando atender as necessidades tanto dos projetos internos como de projetos externos. Mesmo assim, durante a rotina de atendimento do $\mathrm{BDH}$, percebe-se certo desconhecimento da comunidade acadêmica em relação aos objetivos e finalidades do mesmo.

Neste contexto, esta pesquisa foi realizada com o objetivo de determinar o perfil dos usuários do BDH da UFPR, relacionar os tipos de serviços mais procurados, verificar se há a utilização de dentes obtidos fora do BDH e, por fim, avaliar o grau de satisfação dos seus usuários.

\section{MATERIAL E MÉTODOS}

A pesquisa foi aprovada pelo Comitê de Ética em Pesquisa do Setor de Ciências da Saúde da UFPR (CAAE: 11044919. 3.0000.0102; parecer $n^{\circ} 3.415 .911$ ). Para a coleta dos dados, um questionário composto por 19 (dezenove) perguntas foi aplicado utilizando a ferramenta GoogleForms ${ }^{\circledR} \quad$ (Google, Mountain View, CA, EUA). Este instrumento de pesquisa permitiu verificar o conhecimento e a utilização do BDH pela comunidade acadêmica do curso de Odontologia da UFPR. Um pré-teste foi realizado, a partir da aplicação do questionário a um pequeno número de participantes, de modo a detectar falhas na elaboração e apresentação do instrumento, as quais foram corrigidas.

O questionário autoaplicável continha perguntas iniciais referentes aos aspectos sóciodemográficos como sexo, idade, cidade e/ou região de origem e, no caso de aluno, a periodização e, de professores ou servidores, o tempo de vínculo com o curso. Estas questões foram configuradas para permitir apenas uma opção de resposta. $\mathrm{Na}$ sequência, os participantes foram questionados se conheciam o BDH da UFPR, se já tinham utilizado seus serviços e, em caso afirmativo, para qual 
finalidade, estando disponíveis as opções "Empréstimo", "Doação", "Empréstimo e Doação", "Outra" (questão aberta). As perguntas seguintes foram direcionadas para verificar de qual coleção o empréstimo e/ou doação foi realizado, bem como para quais atividades, seja para o ensino, a extensão ou a pesquisa. Estas questões permitiram a escolha de mais de uma opção. O bloco seguinte de perguntas analisou se foram obtidos dentes externamente ao BDH da UFPR e, em caso afirmativo, a procedência e os cuidados relacionados à desinfecção e/ou esterilização, assim como o uso de equipamentos de proteção individual (EPI) durante sua manipulação. Por fim, verificou-se a dificuldade para a obtenção de dentes no BDH da UFPR e de satisfação dos usuários. $\mathrm{O}$ questionário aplicado aos professores do curso teve seis perguntas adicionais, de natureza dicotômica, que objetivaram verificar se os professores já haviam solicitado dentes aos estudantes, se houve dificuldade em sua obtenção e, no caso de dentes obtidos externamente ao $\mathrm{BDH}$ da UFPR, se cuidados foram tomados em relação à desinfecção e/ou esterilização e o uso de EPI, finalizando sobre a importância do BDH para o curso.

Foram incluídos no estudo toda a comunidade acadêmica vinculada ao curso de Odontologia da BDH UFPR, ou seja, discentes, docentes e servidores técnicos administrativos. O convite para a participação da pesquisa foi realizado por correio eletrônico, enviado pelos departamentos, contendo a carta convite, de forma a garantir o sigilo e a confidencialidade no recrutamento. $\mathrm{O}$ convite para participar da pesquisa continha o link para o TCLE e o questionário, bem como $\mathrm{o}$ contato dos pesquisadores. Isto permitiu que o TCLE devidamente assinado fosse obtido, mantendo o sigilo das respostas ao questionário, o qual foi feito de maneira independente e autônoma por via eletrônica. Outra forma de disponibilizar o acesso ao questionário online foi a exposição de banner explicativo com $Q R$ Code que direcionava o participante para a pesquisa. Profissionais não vinculados à UFPR e pacientes em geral foram excluídos deste estudo. A metodologia de utilizar uma ferramenta online permitiu garantir $\mathrm{o}$ anonimato dos entrevistados e também evitar respostas tendenciosas, assim como permitir a análise em tempo real das respostas obtidas.

Os dados foram coletados no período de agosto a dezembro de 2019 e, então, apresentados por meio de estatística descritiva (frequências absoluta e relativa), utilizando a planilha Excel ${ }^{\circledR}$ (Microsoft, Richmond, WA, EUA) extraída da plataforma GoogleForms. Os dados foram agrupados de acordo com o vínculo: estudantes, professores e servidores.

\section{RESULTADOS}

Foram recebidos 300 questionários respondidos, sendo 263 de alunos da graduação (do total de 410 estudantes matriculados), 4 da pós-graduação (1 de especialização e 3 de mestrado), 24 de professores (do total de 96 docentes) e 9 de servidores técnicoadministrativos (do total de 30). Dentre os alunos de pós-graduação, todos conheciam o BDH da UFPR e destes, três (75\%) realizaram empréstimo de dentes não rastreáveis para atividade de ensino quando ainda eram estudantes da graduação e os devolveram após o uso.

No que se refere ao perfil dos usuários do grupo dos estudantes de graduação os resultados mostraram que $75,29 \%$ (198) eram do sexo feminino e $24,71 \%$ (65) do masculino; quanto à faixa etária, 71,86\% (189) estava entre 17 e 22 anos, $21,29 \%$ (56) entre 23 e 25 anos, $4,94 \%$ (13) entre 26 e 29 e $1,91 \%$ (5) entre 30 e 35 anos; já em relação à região de origem, $56,65 \%$ (149) eram de Curitiba, 13,69\% (36) da região metropolitana de Curitiba, 12,55\% (33) do interior do Paraná, 15,59\% (41) de outros 
estados brasileiros, $0,76 \%$ (2) do litoral paranaense, $0,38 \%$ (1) de outro país e $0,38 \%$ (1) não respondeu. A tabela 1 reúne informações sobre o conhecimento e a utilização do BDH da UFPR pelos alunos de graduação de acordo com sua periodização.

Tabela 1. Distribuição de respostas dos estudantes de graduação a três perguntas considerando a periodização

\begin{tabular}{|c|c|c|c|c|c|c|c|}
\hline \multirow[t]{2}{*}{ Periodização } & \multirow{2}{*}{$\begin{array}{c}\mathbf{n}^{\mathbf{0}} \text { de } \\
\text { alunos }\end{array}$} & \multicolumn{2}{|c|}{$\begin{array}{c}\text { Conhece o BDH } \\
\text { da UFPR }\end{array}$} & \multicolumn{2}{|c|}{$\begin{array}{c}\text { Já usou os } \\
\text { serviços do BDH } \\
\text { da UFPR } \\
\end{array}$} & \multicolumn{2}{|c|}{$\begin{array}{c}\text { Já precisou de dentes } \\
\text { e não usou o BDH da } \\
\text { UFPR }\end{array}$} \\
\hline & & $\begin{array}{c}\text { Sim } \\
n(\%)\end{array}$ & $\begin{array}{l}\text { Não } \\
\text { n (\%) }\end{array}$ & $\underset{n(\%)}{\operatorname{Sim}}$ & $\begin{array}{c}\text { Não } \\
\text { n (\%) }\end{array}$ & Sim & $\begin{array}{c}\text { Não } \\
\text { n (\%) }\end{array}$ \\
\hline $1^{\circ}$ período & 40 & $\begin{array}{c}16 \\
(40,0)\end{array}$ & $\begin{array}{c}24 \\
(60,0)\end{array}$ & $\begin{array}{c}2 \\
(5,0)\end{array}$ & $\begin{array}{c}38 \\
(95,0)\end{array}$ & $\begin{array}{c}16 \\
(40,0)\end{array}$ & $\begin{array}{c}24 \\
(60,0)\end{array}$ \\
\hline $2^{\circ}$ período & 10 & $\begin{array}{c}7 \\
(70,0)\end{array}$ & $\begin{array}{c}3 \\
(30,0)\end{array}$ & $\begin{array}{c}4 \\
(40,0)\end{array}$ & $\begin{array}{c}6 \\
(60,0)\end{array}$ & $\begin{array}{c}4 \\
(40,0)\end{array}$ & $\begin{array}{c}6 \\
(60,0)\end{array}$ \\
\hline $3^{\circ}$ período & 34 & $\begin{array}{c}15 \\
(44,12)\end{array}$ & $\begin{array}{c}19 \\
(55,88)\end{array}$ & $\begin{array}{c}1 \\
(2,94)\end{array}$ & $\begin{array}{c}33 \\
(97,06)\end{array}$ & $\begin{array}{c}10 \\
(29,41)\end{array}$ & $\begin{array}{c}24 \\
(70,59)\end{array}$ \\
\hline $4^{\circ}$ período & 33 & $\begin{array}{c}30 \\
(90,91)\end{array}$ & $\begin{array}{c}3 \\
(9,09)\end{array}$ & $\begin{array}{c}5 \\
(15,15)\end{array}$ & $\begin{array}{c}28 \\
(84,85)\end{array}$ & $\begin{array}{c}3 \\
(9,09)\end{array}$ & $\begin{array}{c}30 \\
(90,91)\end{array}$ \\
\hline $5^{\circ}$ período & 33 & $\begin{array}{c}32 \\
(96,97)\end{array}$ & $\begin{array}{c}1 \\
(3,03)\end{array}$ & $\begin{array}{c}21 \\
(63,64)\end{array}$ & $\begin{array}{c}12 \\
(36,36)\end{array}$ & $\begin{array}{c}25 \\
(75,76)\end{array}$ & $\begin{array}{c}8 \\
(24,24)\end{array}$ \\
\hline $6^{\circ}$ período & 29 & $\begin{array}{c}29 \\
(100)\end{array}$ & $\begin{array}{c}0 \\
(0)\end{array}$ & $\begin{array}{c}27 \\
(93,1)\end{array}$ & $\begin{array}{c}2 \\
(6,9)\end{array}$ & $\begin{array}{c}26 \\
(89,66)\end{array}$ & $\begin{array}{c}3 \\
(10,34)\end{array}$ \\
\hline $7^{\circ}$ período & 28 & $\begin{array}{c}28 \\
(100)\end{array}$ & $\begin{array}{c}0 \\
(0)\end{array}$ & $\begin{array}{c}24 \\
(85,71)\end{array}$ & $\begin{array}{c}4 \\
(14,29)\end{array}$ & $\begin{array}{c}27 \\
(96,43)\end{array}$ & $\begin{array}{c}1 \\
(3,57)\end{array}$ \\
\hline $8^{\circ}$ período & 25 & $\begin{array}{c}25 \\
(100)\end{array}$ & $\begin{array}{c}0 \\
(0)\end{array}$ & $\begin{array}{c}21 \\
(84,0)\end{array}$ & $\begin{array}{c}4 \\
(16,0)\end{array}$ & $\begin{array}{c}20 \\
(80,0)\end{array}$ & $\begin{array}{c}5 \\
(20,0)\end{array}$ \\
\hline $9^{\circ}$ período & 26 & $\begin{array}{c}26 \\
(100)\end{array}$ & $\begin{array}{c}0 \\
(0)\end{array}$ & $\begin{array}{c}25 \\
(96,15)\end{array}$ & $\begin{array}{c}1 \\
(3,85)\end{array}$ & $\begin{array}{c}22 \\
(84,62)\end{array}$ & $\begin{array}{c}4 \\
(15,38)\end{array}$ \\
\hline $\begin{array}{l}\text { Desperio- } \\
\text { dizados }\end{array}$ & 5 & $\begin{array}{c}5 \\
(100)\end{array}$ & $\begin{array}{c}0 \\
(0)\end{array}$ & $\begin{array}{c}2 \\
(40,0)\end{array}$ & $\begin{array}{c}3 \\
(60,0)\end{array}$ & $\begin{array}{c}3 \\
(60,0)\end{array}$ & $\begin{array}{c}2 \\
(60,0)\end{array}$ \\
\hline Total (\%) & $\begin{array}{c}263 \\
(100)\end{array}$ & $\begin{array}{c}213 \\
(80,99)\end{array}$ & $\begin{array}{c}50 \\
(19,01)\end{array}$ & $\begin{array}{c}132 \\
(50,19)\end{array}$ & $\begin{array}{c}131 \\
(49,81)\end{array}$ & $\begin{array}{c}156 \\
(59,32)\end{array}$ & $\begin{array}{c}107 \\
(40,68)\end{array}$ \\
\hline
\end{tabular}

As tabelas 2 e 3 apresentam a síntese dos dados coletados dos questionários dos alunos, sendo a primeira referente aos serviços do $\mathrm{BDH}$ da UFPR que foram utilizados, finalidade, coleção e destino após uso, enquanto a segunda mostra as respostas relacionadas aos dentes obtidos externamente com relação à procedência, desinfecção e/ou esterilização, métodos empregados e uso de EPI.

O grau de dificuldade para a obtenção de dentes para as atividades do curso foi considerado moderado por $38,4 \%$ dos alunos (figura 1). Já o seu grau de satisfação com os serviços prestados pelo BDH da UFPR, variou em função do período em curso (figura 2).

No grupo dos servidores, entre os professores $58,3 \%$ (14) eram do sexo masculino e $41,7 \%$ (10) do feminino e entre os técnicos administrativos $66,7 \%$ (6) eram do sexo feminino, enquanto $33,3 \%$ (3) do masculino. A faixa etária dos professores variou entre 30 e 75 anos, com maior ocorrência entre 40 e 59 anos $(58,3 \%)$ e a dos técnicos administrativos ficou entre 26 e 75 anos, com maior número de 
respostas entre 47 e 59 anos (44,4\%). Quanto ao tempo de vínculo que o servidor tinha com o curso de Odontologia, 52,2\% dos professores apresentavam mais de 10 anos, 43,5\%, entre 4 e 10 anos e 4,3\% entre 1 e 3 anos. Já entre os técnicos administrativos, 44,5\% possuíam vínculo pelo tempo de 4 a 10 anos, 33,3\% mais de 10 anos, $11,1 \%$ entre 1 e 3 anos e 11,1\% por menos de um ano.

Quando questionados se conheciam o BDH da UFPR, 100\% dos servidores disseram que sim. Dentre os professores,
$79,2 \%$ (19) relataram já ter utilizado os serviços do BDH da UFPR, contra apenas $11,1 \%$ (1) dos técnicos administrativos, o qual realizou uma doação de dentes rastreáveis. A síntese das respostas dos professores com relação aos serviços utilizados, finalidade, coleção e destino após uso estão descritos na tabela 4. Os dentes obtidos externamente ao BDH da UFPR estão descritos na tabela 5, com relação à procedência, desinfecção e/ou esterilização, métodos para desinfecção e/ou esterilização e uso de EPI.

Tabela 2. Síntese das respostas dos estudantes de graduação que utilizaram os serviços do BDH da UFPR (n=132), quanto à coleção, finalidade e destino após o uso

\begin{tabular}{|c|c|c|}
\hline Variáveis & $\mathbf{n}$ & $\%$ \\
\hline Empréstimo & 75 & 56,82 \\
\hline Dentes rastreáveis & - & - \\
\hline Dentes não rastreáveis & 121 & 100 \\
\hline Ensino & 101 & 83,47 \\
\hline Pesquisa & 2 & 1,65 \\
\hline Extensão & 1 & 0,83 \\
\hline Ensino e extensão & 11 & 9,09 \\
\hline Ensino e pesquisa & 6 & 4,96 \\
\hline Devolveram & 51 & 42,15 \\
\hline Mantiveram & 33 & 27,27 \\
\hline Ficou com o professor & 7 & 5,79 \\
\hline Não sabiam & 4 & 3,31 \\
\hline Descartaram & 3 & 2,48 \\
\hline Não responderam & 23 & 19,01 \\
\hline Doação & 7 & 5,30 \\
\hline Dentes rastreáveis & 46 & 85,65 \\
\hline Acervo do banco de dentes & 45 & 83,83 \\
\hline Pesquisa própria & 1 & 1,82 \\
\hline Dentes não rastreáveis & 2 & 3,64 \\
\hline Acervo do banco de dentes & 1 & 1,82 \\
\hline Pesquisa própria & 1 & 1,82 \\
\hline Dentes rastreáveis e não rastreáveis & 6 & 10,91 \\
\hline Acervo do banco de dentes & 4 & 7,27 \\
\hline Pesquisa própria & 2 & 3,64 \\
\hline Empréstimo e doação* & 46 & 34,85 \\
\hline Outra** & 4 & 3,03 \\
\hline
\end{tabular}


Tabela 3. Síntese das respostas dos estudantes de graduação que obtiveram dentes externamente ao BDH da UFPR ( $\mathrm{n}=156)$, quanto à procedência, método para desinfecção ou esterilização e uso de EPI

\begin{tabular}{lcc}
\hline Variáveis & n & \% \\
\hline Procedência & 57 & 36,54 \\
Consultório particular & 25 & 16,03 \\
Departamento de anatomia & 11 & 7,05 \\
Colegas de curso & 10 & 6,41 \\
Rede Pública de Saúde & 49 & 31,41 \\
Mais de um local & 6 & 2,56 \\
Não responderam & & \\
Realizaram desinfecção e/ou esterilização & 89 & 57,05 \\
Sempre & 37 & 23,72 \\
Às vezes & 30 & 19,23 \\
Nunca & & 44,23 \\
Métodos para Desinfecção e/ou Esterilização & 69 & 5,77 \\
Autoclave & 9 & 3,85 \\
Ácido Peracético & 6 & 2,56 \\
Hipoclorito de sódio & 4 & 16,03 \\
Álcool 70\% & 25 & 2,56 \\
Associação de métodos & 4 & 25,00 \\
Levou ao banco de dentes & 36 & \\
Não responderam & & 55,13 \\
Sim & 86 & 20,51 \\
Não & 32 & 24,36 \\
Não responderam & 38 &
\end{tabular}

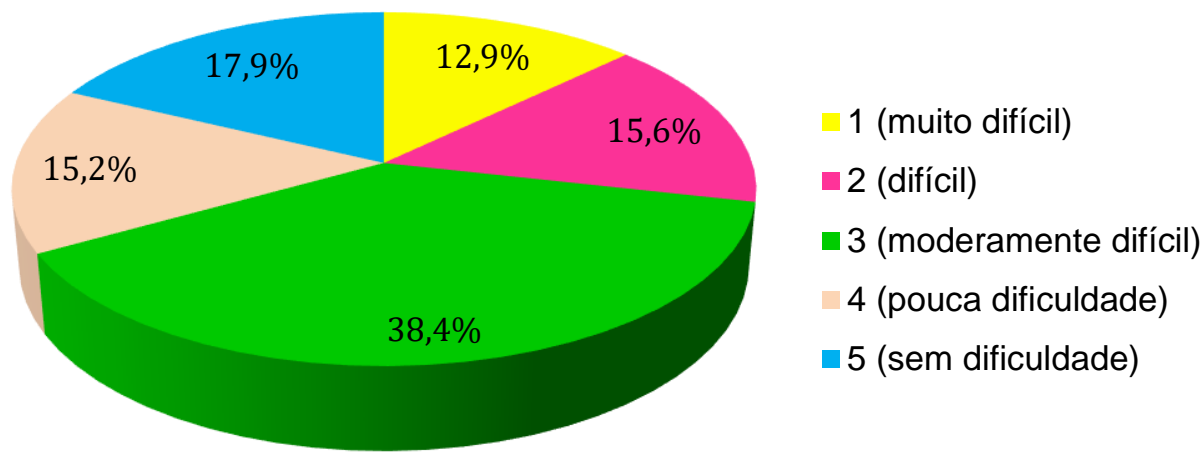

Figura 1. Grau de dificuldade apontado pelos estudantes para a obtenção de dentes 


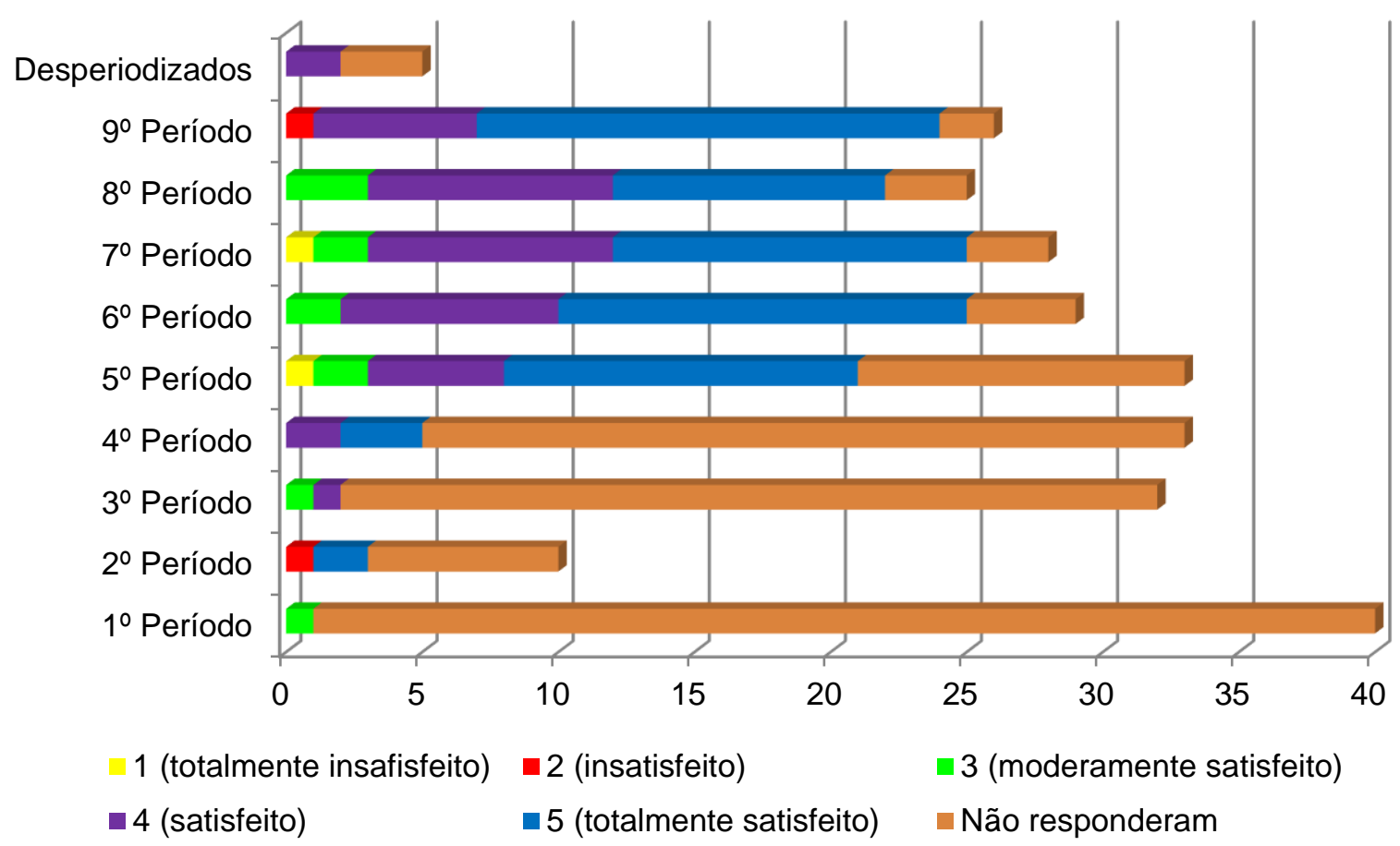

Figura 2. Grau de satisfação com os serviços do BDH da UFPR indicado pelos estudantes, de acordo com a periodização

Tabela 4. Síntese das respostas dos professores que utilizaram os serviços do BDH da UFPR $(\mathrm{n}=19)$, quanto à coleção, finalidade e destino após o uso

\begin{tabular}{lcc}
\hline Variáveis & $\mathbf{n}$ & $\%$ \\
\hline Empréstimo & 2 & 10,5 \\
$\quad \begin{array}{l}\text { Dentes não rastreáveis para ensino e/ou } \\
\text { extensão }\end{array}$ & 5 & 42,3 \\
$\quad \begin{array}{l}\text { Dentes rastreáveis e/ou não rastreáveis para } \\
\text { pesquisa }\end{array}$ & 7 & 57,7 \\
Devolveram & 7 & 63,6 \\
Devolveram parcialmente & 3 & 18,2 \\
Mantiveram & 1 & 9,1 \\
Descartaram & 1 & 9,1 \\
Doação para o acervo do banco de dentes & 6 & 31,6 \\
$\quad$ Dentes rastreáveis & 3 & 20,0 \\
$\quad$ Dentes não rastreáveis & 12 & 80,0 \\
Empréstimo e doação* & 9 & 47,4 \\
Outra** & 2 & 10,5 \\
\hline Dentre os participantes que informaram terem tanto emprestado quanto doado dentes ao BDH da UFPR, a \\
coleção e a finalidade foram alocados no grupo de empréstimo ou doação, respectivamente. Para os empréstimos, \\
como foram indicadas mais de uma finalidade, as respostas foram organizadas e categorizadas em dois grupos. \\
** Preparo de dentes para a realização de pesquisa.
\end{tabular}


Tabela 5. Síntese das respostas dos professores que obtiveram dentes externamente ao BDH da UFPR (n=6), quanto à procedência, método para desinfecção ou esterilização e uso de EPI

\begin{tabular}{llc}
\hline Variáveis & n & \% \\
\hline Procedência & 1 & 11,1 \\
Consultório particular & 1 & 11,1 \\
Departamento de anatomia & 1 & 11,1 \\
Alunos do curso & 3 & 66,7 \\
$\quad$ Consultório particular e Rede Pública de Saúde & & 66,7 \\
Realizaram desinfecção e/ou esterilização & 4 & 33,3 \\
Sempre & 2 & - \\
Às vezes & - & 33,3 \\
Nunca & & 16,7 \\
Métodos para Desinfecção e/ou Esterilização & 2 & 33,3 \\
Autoclave & 1 & 16,7 \\
Autoclave + álcool 70\% & 2 & 100,0 \\
Autoclave + hipoclorito de sódio & 1 & - \\
Levou ao banco de dentes & & \\
Uso de Equipamentos de proteção individual & 6 & - \\
Sim & & \\
Não &
\end{tabular}

O grau de dificuldade para a obtenção de dentes foi apontado pelos professores como sendo muito difícil $(8,3 \%)$, difícil $(4,2 \%)$, moderadamente difícil $(29,2 \%)$, pouca dificuldade $(8,3 \%)$ e sem dificuldade $(50 \%)$. Quanto ao grau de satisfação em relação aos serviços prestados pelo BDH da UFPR, 70,8\% dos professores responderam estarem totalmente satisfeitos, enquanto $29,2 \%$ não responderam. As respostas da parte do questionário destinada apenas aos professores do curso são apresentadas na tabela 6 .

Tabela 6. Distribuição de respostas das questões exclusivas para os professores.

\begin{tabular}{|c|c|c|c|}
\hline Perguntas & $\underset{\mathbf{n}(\%)}{\operatorname{Sim}}$ & $\begin{array}{l}\text { Não } \\
\text { n }(\%)\end{array}$ & $\begin{array}{c}\text { Não responderam } \\
\text { n }(\%)\end{array}$ \\
\hline Já solicitou aos alunos dentes naturais para & 9 & 13 & $\begin{array}{c}2 \\
(8)\end{array}$ \\
\hline uso em laboratório ou pesquisa acadêmica? & $(37,5 \%)$ & $(54,2 \%)$ & $(8,3 \%)$ \\
\hline $\begin{array}{l}\text { Teve dificuldade em encontrar todos os } \\
\text { elementos dentários necessários? }\end{array}$ & $\begin{array}{c}7 \\
(29,2 \%)\end{array}$ & $\begin{array}{c}10 \\
(41,6 \%)\end{array}$ & $\begin{array}{c}7 \\
(29,2 \%)\end{array}$ \\
\hline $\begin{array}{l}\text { Os alunos relataram dificuldade em obter os } \\
\text { dentes solicitados? }\end{array}$ & $\begin{array}{c}8 \\
(33,3 \%)\end{array}$ & $\begin{array}{c}10 \\
(41,6 \%)\end{array}$ & $\begin{array}{c}6 \\
(25,1 \%)\end{array}$ \\
\hline $\begin{array}{l}\text { Quando os elementos são externos ao BDH } \\
\text { da UFPR, é solicitada a desinfecção e } \\
\text { esterilização prévia? }\end{array}$ & $\begin{array}{c}13 \\
(54,2 \%)\end{array}$ & $\begin{array}{c}2 \\
(8,3 \%)\end{array}$ & $\begin{array}{c}9 \\
(37,5 \%)\end{array}$ \\
\hline $\begin{array}{l}\text { Requer o uso e equipamentos de proteção } \\
\text { individual no manuseio destes dentes? }\end{array}$ & $\begin{array}{c}16 \\
(66,7 \%)\end{array}$ & $\begin{array}{c}0 \\
(0 \%)\end{array}$ & $\begin{array}{c}8 \\
(33,3 \%)\end{array}$ \\
\hline $\begin{array}{l}\text { Considera importante a existência do BDH } \\
\text { da UFPR para suporte das atividades } \\
\text { acadêmicas do curso? }\end{array}$ & $\begin{array}{c}20 \\
(83,3 \%)\end{array}$ & $\begin{array}{c}0 \\
(0 \%)\end{array}$ & $\begin{array}{c}4 \\
(16,7 \%)\end{array}$ \\
\hline
\end{tabular}




\section{DISCUSSÃO}

A comunidade acadêmica do curso de Odontologia da UFPR demonstrou, em sua grande maioria, saber da existência do BDH e utilizá-lo tanto para o empréstimo quanto para a doação de dentes. Entre os alunos o principal serviço utilizado foi o empréstimo de dentes não rastreáveis para atividades de ensino, enquanto entre os professores a maior ocorrência foi a realização de empréstimo e doação. Os participantes da pesquisa que apontaram não conhecer o BDH eram estudantes dos primeiros períodos do curso, sendo que a maioria $(89,74 \%)$ cursava do $1^{\circ}$ ao $4^{\circ}$ período. Isto pode ser explicado pelo fato de ainda não terem iniciado as disciplinas com práticas laboratoriais pré-clínicas que solicitam dentes naturais e que a disciplina de Anatomia Dental da UFPR, ofertada no $1^{\circ}$ período do curso, possui um acervo próprio de dentes extraídos.

A partir do $5^{\circ}$ período houve um aumento significativo na utilização dos serviços $\mathrm{BDH}$ da UFPR, o que se deve à oferta da disciplina de Endodontia I neste período, a qual é pré-clínica. Segundo Medeiros et al. (2020) ${ }^{12}$ a Endodontia é a área de formação que mais utiliza dentes humanos extraídos para a realização de atividades práticas laboratoriais. Estudos prévios que compararam o uso de dentes artificiais e naturais para o aprendizado da Endodontia mostraram que embora os dentes artificiais possuam aspectos favoráveis para o treinamento inicial dos alunos, seu uso deve ser cauteloso, pois apresentam limitações como dureza insatisfatória da resina ${ }^{13}$, dificuldade de irrigação e obturação do canal, bem como na interpretação radiográfica ${ }^{14} \mathrm{e}$, ainda, mostram diferenças morfológicas e morfométricas quando comparados aos dentes naturais ${ }^{15}$. Assim, a utilização de dentes humanos extraídos foi apontada como mais confiável para o sucesso do treinamento pré-clínico ${ }^{16,17}$.

Um resultado que chamou a atenção foi o fato de que $75,76 \%$ dos alunos do $5^{\circ}$ período relataram ter precisado de dentes, mas não utilizaram o BDH da UFPR. Esta alta porcentagem de alunos que obtiveram dentes de fontes externas se mostra recorrente nos demais períodos a partir do $5^{\circ}$. Isto gera preocupação ética e legal, bem como em relação à biossegurança durante o manuseio destes dentes. No que se refere à forma de obtenção, verificou-se que a compra de elementos dentários foi muito pequena $(0,64 \%)$, sendo a doação o principal meio de aquisição e os consultórios particulares, o local mais comumente indicado como a origem dos dentes doados. Estudos anteriores já demonstraram a preocupação em relação à comercialização de dentes entre os estudantes de Odontologia. Neste sentido, a porcentagem de alunos que relataram ter comprado dentes para 0 desenvolvimento de atividades práticas durante o curso variou entre $1,2 \%$ a $11 \%^{12,18,19}$. Os achados do presente estudo, quando comparados à literatura ${ }^{12,18,19}$ sugerem ter havido uma maior conscientização dos alunos a respeito da ilegalidade do comércio de dentes. O desconhecimento de parte dos alunos dos primeiros períodos da existência do $\mathrm{BDH}$ da UFPR e, portanto, do seu objetivo e serviços prestados, bem como o grande número de estudantes que buscaram dentes externamente, levou a equipe do BDH a implementar novas ações de conscientização da comunidade interna, como palestra e visita guiada dos ingressantes no curso, atualização do site do $\mathrm{BDH}$ da UFPR, incluindo materiais informativos, acesso aos POP, manuais, legislações, termos (para doação e empréstimo) e atividades desenvolvidas, bem como postagens frequentes nos perfis do $\mathrm{BDH}$ em redes sociais.

Os dentes são fontes potenciais de contaminação, pois podem conter diversos patógenos e, portanto, devem ser submetidos a procedimentos de desinfecção e esterilização antes de serem utilizados por estudantes de 
Odontologia nas suas atividades pré-clínicas. Para isso, o uso dos EPIs é fundamental e indispensável ${ }^{1,10,20,21}$. Os resultados desta pesquisa mostraram uma grande diversidade de respostas, tanto dos alunos quanto dos professores, a respeito do protocolo adotado para a desinfecção e/ou esterilização dos dentes extraídos. Porém, a esterilização por meio de autoclave foi o método mais indicado pelos participantes. Esta diversidade de respostas sobre os procedimentos de desinfecção/ esterilização de dentes extraídos também é bastante observada na literatura ${ }^{12,19}$.

O protocolo para os dentes não rastreáveis que chegam ao BDH da UFPR inicia-se pela limpeza em lavadora ultrassônica com sabão enzimático, seguida por desinfecção com ácido peracético a $1 \% \mathrm{e}$, então, a esterilização em autoclave a $121^{\circ} \mathrm{C}$ por 35 minutos. Segundo Demenech et al. $(2017)^{22}$, o uso de lavadora ultrassônica favorece a remoção de resíduos em camadas mais profundas e regiões de difícil acesso, enquanto a autoclavagem tem sido apontada como um método seguro e eficiente de esterilização ${ }^{21,22}$. O ácido peracético é usado durante o processamento dos dentes por ser um desinfetante de alto nível e apresentar características como ser bactericida, viruscida, fungicida e esporicida, com descarte facilitado por não formar resíduos tóxicos, ser biodegradável, efetivo na presença de matéria orgânica e possuir rápida ação em baixas temperaturas ${ }^{23}$. Devido à potencial liberação de vapores de mercúrio de restaurações de amálgama, os dentes que apresentam este material restaurador não são inicialmente esterilizados em autoclave, apenas limpos e desinfetados, minimizando os riscos associados. ${ }^{21} \mathrm{~A}$ remoção do amálgama é feita posteriormente, dentro de caixa acrílica adaptada, coletando-se os resíduos e, então submetidos à esterilização. Como rotina, os dentes rastreáveis são limpos, desinfetados com ácido peracético a $1 \%$ e, então, acondicionados em cloramina $\mathrm{T}$ a $0,5 \%$ e mantidos sob refrigeração $\left(\sim 4^{\circ} \mathrm{C}\right)$. A não esterilização objetiva preservar as características dos tecidos dentais $^{22}$. Diversas soluções desinfetantes tem sido estudadas para o armazenamento de dentes a serem utilizados em pesquisa, contudo ainda não há um consenso ${ }^{22,24}$.

Um dado que nos chamou a atenção foi que $19,23 \%$ dos alunos relataram não utilizar EPI para a realização dos procedimentos de desinfecção e/ou esterilização. Contudo, diversos estudos ressaltam a importância do uso dos EPI para o manuseio dos dentes humanos extraídos ${ }^{1,18,21}$. Isto mostra que ainda é necessário ampliar as campanhas de conscientização entre os estudantes de Odontologia a respeito das medidas de biossegurança, algo que vem sendo realizado através de divulgação nas mídias sociais do $\mathrm{BDH}$.

Os resultados mostraram que há um desequilíbrio entre o número de doações e de empréstimos, havendo mais alunos realizando empréstimos do que doações. Sabe-se que as doações não dependem apenas da vontade do aluno, pois o paciente deve concordar e assinar um TCLE para tal ação. Deste modo, é preciso investir em campanhas de conscientização para incentivar as doações e torná-las um programa contínuo $^{10}$. Na questão de devolução dos dentes ao BDH após a utilização, menos da metade dos alunos relataram ter devolvido. Contudo, é importante que a devolução ocorra, independentemente do grau de destruição ou desgaste que apresentam, para que o $\mathrm{BDH}$ possa fazer o controle e gestão dos dentes emprestados $^{25}$. Neste sentido, o Termo de Empréstimo foi atualizado de modo que tenha, no mesmo documento, informações para a devolução, visando reforçar a necessidade desta ação.

O BDH da UFPR tem como uma de suas missões fornecer, de maneira segura e por meio 
de empréstimo ou cessão, dentes extraídos à comunidade acadêmica do curso de Odontologia e, neste sentido, buscou saber o grau de dificuldade para sua obtenção. Entre os alunos, a resposta mais frequente foi "moderadamente difícil" (38,4\%), seguido de "sem dificuldade" (17,87\%), enquanto 50\% dos professores relataram que não houve dificuldade. Estes achados, associados à porcentagem de alunos que recorrem a fontes externas para a obtenção de dentes extraídos demonstram que as ações de divulgação do BDH da UFPR precisam ser ampliadas, o que já vem sendo implementado. No que se refere à satisfação dos usuários quanto aos serviços prestados pelo BDH da UFPR foi possível observar que as respostas mais freqüentes, entre os estudantes, foram "totalmente satisfeito" (16,09\%) e "satisfeito" (27,97\%). Entre os professores, 70,8\% relataram estar "totalmente satisfeitos".

A parte do questionário destinada exclusivamente aos professores mostrou que quando são solicitados dentes extraídos para a realização das atividades pré-clínicas, 33,3\% dos alunos relataram ter tido dificuldade para sua obtenção. Isto pode ser explicado, em parte, pela quantidade de elementos dentários de um mesmo grupo requerido para os estudantes. Como o BDH da UFPR é mantido a partir de doações tanto internas como externamente à universidade e, embora haja parcerias com a Secretaria Municipal de Saúde de Curitiba e de Piraquara, a quantidade de dentes de um determinado grupo dentário pode não ser suficiente para suprir a demanda do curso. Isto faz com que seja necessário ampliar o número de parcerias e de campanhas de divulgação, de modo a se aumentar a captação de dentes, conforme recomendam Miranda e Bueno $(2012)^{10}$. Contudo, a grande maioria dos professores do curso considera importante a existência do BDH da UFPR para dar suporte às atividades didáticas desenvolvidas ao longo do curso de Odontologia.

A maior dificuldade na realização da pesquisa foi a adesão dos participantes, porém a estratégia de disponibilização do banner parece ter sido favorável, principalmente entre os estudantes. A partir dos resultados desta pesquisa, o BDH da UFPR implementou novas ações com o objetivo de ampliar a disseminação de informações sobre a doação e sua importância, biossegurança e aspectos éticos e legais, usando principalmente as mídias sociais. Assim, o estudo contribuiu para a incorporação de novas estratégias e auxiliar outros bancos de dentes no planejamento de suas ações.

\section{CONCLUSÕES}

A maior parte do corpo discente e todos os servidores (professores e técnicos administrativos) sabem da existência do BDH da UFPR. O serviço mais utilizado pelos estudantes é o empréstimo de dentes não rastreáveis para a realização de atividades de ensino nas aulas laboratoriais pré-clínicas. Entre os professores, o mais frequente foi a realização de ambos: empréstimos, predominantemente para a atividades de pesquisa e doações de dentes não rastreáveis. Entretanto, menos da metade dos alunos relataram ter devolvido os dentes após sua utilização, ao passo que entre os professores houve uma maior percentagem de devolução, embora bastante aquém da totalidade. Muitos estudantes buscaram dentes externamente e o principal local apontado foram os consultórios e clínicas particulares. Ainda, parte destes dentes não foi submetida aos procedimentos de desinfecção e/ou esterilização e os estudantes nem sempre usaram EPI durante sua manipulação. Diante destes achados, ressalta-se a importância de ampliar as ações quanto à conscientização da comunidade acadêmica tanto a respeito da existência do BDH da UFPR quanto da sua missão e, deste modo, diminuir ou mesmo erradicar a obtenção de dentes de maneira 
ilícita, ou seja, não provenientes de um banco de dentes, bem como sobre os cuidados durante seu manuseio no que tange à biossegurança.

\section{ABSTRACT \\ Knowledge and use of the Human Teeth Biobank by the academic community of the UFPR Dentistry course}

This study aimed to analyze the profile of users of the Human Teeth Biobank at the Federal University of Paraná (HTB-UFPR), the most sought-after services, whether externally obtained teeth are used and the degree of user satisfaction. For this, a semistructured electronic questionnaire was applied to the internal community of the Dentistry course at UFPR, between August and December 2019. A total of 300 questionnaires were answered, 263 by undergraduate students, 4 by graduate students, 24 by professors and 9 by technicaladministrative employees. Most students were female between 17 and 22 years old, while for employees (teachers and technicians) there was a similar distribution between the sexes in the age group between 40 and 59 years old. Although $80.99 \%$ of the students claimed to know the HTB-UFPR, only $50.19 \%$ used its services and $59.32 \%$ reported having already looked for teeth externally. The most used service was the withdrawal for teaching activities, but only $42.15 \%$ returned them after use. The teeth obtained externally came mainly from private offices and only $56.33 \%$ of the students reported having always submitted them to disinfection/sterilization, with the autoclave being the most indicated method. All employees knew the HTB-UFPR and, among the teachers, most made both withdrawal and donations. The main purpose of the withdrawals was the research and $63.6 \%$ reported having returned their teeth. As for satisfaction, the academic community was predominantly fully satisfied. Finally, it emphasizes the need to expand awareness actions for the academic community regarding ethical, legal and biosafety aspects in the acquisition and manipulation of human teeth.
Descriptors: Tooth. Dental Ethics. Dentistry

Education. Research in Dentistry.

\section{REFERÊNCIAS}

1. Costa SM, Ferreira SM, Pires CPAB, Otoni AFBB, Freitas DM, Popoff DAV. Banco de dentes humanos: legalidade, ética e biossegurança. Rev Intercâmbio. 2017; 8:1-15.

2. Brasil. Ministério da Saúde. Portaria $n^{\circ}$ 2.201, de 14 de setembro de 2011. Estabelece as diretrizes nacionais para Biorrepositório e Biobanco de material biológico humano com finalidade de Pesquisa. [Acesso em 10 jul. 2019]. Disponível em: bvsms.saude.gov.br/bvs/ saudelegis/gm/2011/prt2201_14_09_2011 .html.

3. Pereira DQ. Banco de dentes humanos no Brasil: revisão de literatura. Rev ABENO. 2012;12(2):178-84.

4. Freitas ABDA, Pinto SL, Tavares EP, Barros LM, Castro CDL, Magalhães CS. Uso de dentes humanos extraídos e os bancos de dentes nas instituições brasileiras de ensino de odontologia. Pesqui Bras Odontopediatria Clin Integr. 2012;12(1):59-64.

5. Endo MS, Silva IRG, da Silva MC, Terada RSS, Rocha NB. A importância do banco de dentes humanos: relato de experiência. Arch Health Invest. 2017;6(10):486-90.

6. Chalisserry EP, Nam SY, Park SH, Anil S. Therapeutic potential of dental stem cells. J Tissue Eng. 2017;8:1-7.

7. Brasil. Lei $n^{\circ} 9.434$ de 4 de fevereiro de 1997. Dispõe sobre a remoção de órgãos, tecidos e partes do corpo humano para fins de transplante e tratamento e dá outras providências. [Acesso em 15 out. 2018]. Disponível em: https://www.planalto. gov.br/ccivil_03/leis/19434.htm.

8. Nassif ACS, Tieri F, da Ana PA, Botta SB, Imparato JCP. Estruturação de um banco 
de dentes humanos. Pesq Odontol Bras. 2003;17(supl 1):70-4.

9. Ghiggi LD, Dallanora LMF. Implantação do banco de dentes humanos (BDH) do curso de Odontologia da Universidade do Oeste de Santa Catarina. Ação Odonto. 2014;2:61-71.

10. Miranda GE, Bueno FC. Banco de dentes humanos: uma análise bioética. Rev Bioet. 2012;20(2):255-66.

11. Begosso MP, Imparato JCP, Duarte DA. Estágio atual da organização dos bancos de dentes humanos nas faculdades de Odontologia do território brasileiro. RPG Rev Pos-Grad. 2001;8(1):23-8.

12. Medeiros MCS, Costa ICC, Silva EM, Silva LCA, Santos DA, Paiva DFF. Conhecimento de docentes e discentes de um curso de Odontologia sobre os aspectos legais que envolvem a utilização de dentes humanos extraídos. Rev ABENO. 2020;20(1):13-25.

13. Nassri MR, Carlik J, da Silva CR, Okagawa RE, Lin S. Critical analysis of artificial teeth for endodontic teaching. $\mathrm{J}$ Appl Oral Sci. 2008;16(1):43-9.

14. Luz DS, Ourique FS, Scarparo RK, VierPelisser FV, Morgental RD, Waltrick SBG et al. Preparation time and perceptions of Brazilian specialists and dental students regarding simulated root canals for endodontic teaching: a preliminary study. J Dent Educ. 2015;79(1):56-63.

15. Mendes JS, Montagner F, de Melo TAF, Luisi SB. Avaliação de dentes monorradiculares artificiais utilizados para treinamento endodôntico. Rev Odontol UNESP. 2020;49:e20200018.

16. Bitter K, Gruner D, Wolf O, Schwendicke F. Artificial versus natural teeth for preclinical endodontic training: a randomized controlled trial. J Endod. 2016;42(8):1212-7.
17. da Silva IB, Ferreira TT, da Silva EGF, Barros ABA, Franco LLMM, Silva BSF et al. Percepção de docentes de Odontologia sobre o uso de dentes humanos como recurso educativo em atividades préclínicas. Rev ABENO. 2020;20(2):57-63.

18. Costa SM, Mameluque S, Brandão EL, Melo AEMA, Pires CPAB, Rezende EJC et al. Denteshumanos no ensino odontológico: procedência, utilização, descontaminação, e armazenamento pelos acadêmicos da Unimontes. Rev ABENO. 2007;7(1):7-12.

19. Felipe EF, da Costa GBM, Jank Junior N, da Costa JA. Aspectos éticos da obtenção de dentes por estudantes de uma graduação em Odontologia. Rev Bioét. 2014; 22(1):171-5.

20. Deogade SC, Mantri SS, Saxena S, Sumathi K. Awareness and knowledge of undergraduate dental students about sterilization/disinfection methods of extracted human teeth. Ann Med Health Sci Res. 2016;6(6):348-55.

21. Sethi AK, Samal R, Lahiri B, Das A, Kumar G, Behera S. Awareness, attitude and practice regarding disinfection and handling of extracted teeth among the students in a Dental College in India. J Int Soc Prev Community Dent. 2018;8(6):488-94.

22. Demenech LS, Tomazinho FSF, Tomazinho PH, Gabardo MCL, BarattoFilho F. Avaliação de métodos de manutenção da esterilidade do órgão dental humano extraído para armazenamento em banco de dentes. Rev ABENO. 2017;17(3):55-65.

23. Brasil. Ministério da Saúde. Agência Nacional de Vigilância Sanitária. Serviços odontológicos: prevenção e controle de riscos. Brasília: ANVISA; 2006. [Acesso em 12 mar. 2019]. Disponível em: 
https://www.anvisa.gov.br/servicosaude/ manuais/manual_odonto.pdf.

24. Gadonski AP, Maran BM, De Andrade GS, Naufel FS, Schmitt VL. Avaliação do efeito de soluções de armazenamento sobre a resistência da união adesiva à dentina de dentes bovinos sob microcisalhamento - pesquisa in vitro. Rev Odontol UNESP. 2018; 47(6): 354-9.

25. Moreira L, Genari B, Stello R, Collares FM, Samuel SMW. Banco de Dentes Humanos para o ensino e pesquisa em Odontologia. Rev Fac Odontol Porto Alegre. 2009;50(1):34-7.

\section{Correspondência para:}

Andresa Carla Obici

e-mail: andresaobici@yahoo.com /

obici@ufpr.br

Rua Governador Agamenon Magalhães, 55/303 A

Bairro Cristo Rei

80050-510 Curitiba/PR 